\title{
Distribution, status and conservation of primates in Monte Alen National Park, Equatorial Guinea
}

\author{
Juan E. Garcia and Jesus Mba
}

Equatorial Guinea has a new network of protected areas, but only Monte Alen National Park has any effective protection. As a contribution to the knowledge of this area, a survey of primate populations was carried out during a 7-month period in 1994. The results showed that there is a high primate diversity (15-16 distinct species) in Monte Alen. The three most commonly sighted monkey species were Cercopithecus nictitans (35.9-40.8 per cent of sightings), Cercopithecus cephus (28.9-43.5 per cent) and Cercopithecus pogonias (17.4-22.4 per cent). Mean distance covered to find any group of these guenons varied from $1.1 \mathrm{~km}$ in open primary forest to $2.7 \mathrm{~km}$ in dense primary forest. Gorilla nests were more abundant in secondary forest near villages (5.15 nests $/ \mathrm{km}$ ), while chimpanzee nests were mostly found in primary forest $(5.35$ nests $/ \mathrm{km}$ ). Hunting pressure appears to be low but shifting agriculture has a significant impact on the conservation of the area. The degree of threat varies between species. Alternatives for better management of the area, such as educational programmes and sustainable use of natural resources, are suggested.

\section{Introduction}

Equatorial Guinea has a relatively new network of protected areas (Fa, 1992). From 1986 to 1990 the Spanish Technical Co-operation developed a Conservation and Research Programme (Castroviejo et al., 1994) as a result of which, by 1988, the Ecuato-Guinean Government designated nine zones as protected areas covering a total of $3400 \mathrm{sq} \mathrm{km} \mathrm{(8.2}$ per cent of the country's total land surface). Of these, however, only the Monte Alen area, now the Monte Alen National Park, has effective protection. Since 1992 the programme 'Conservation and Rational Utilization of Tropical Forest Ecosystems in Central Africa' (ECOFAC) has been responsible for overseeing the park. ECOFAC is supported by the European Union; AGRECO-CIRAD Forêt and the Asociación Amigos del Coto de Doñana implement the programme.

One of the main objectives of the ECOFAC project in Monte Alen is to study biodiversity in the area and to reduce hunting pressure through the development of sustainable activities for the local people. To this end, a study of the primates of Monte Alen National Park was conducted during a 7-month period in 1994. This study carried out a general survey of the primate populations in the area including: (i) an inventory of the primate species; (ii) an estimation of their relative abundance, with special attention paid to diurnal species (mangabeys, guenons, colobus, gorillas and chimpanzees); (iii) an evaluation of their conservation status; and (iv) a study of the interactions between the fauna and the traditional activities of the human inhabitants of the area, with specific reference to the impact of different primate species on native food plantations. In this report we present data on the distribution, relative abundance and conservation status of the primate species. 


\section{Study area and methods}

Monte Alen National Park covers approximately $800 \mathrm{sq} \mathrm{km}$ of equatorial forest in the continental region of Equatorial Guinea, Rio Muni (Figure 1). There are two rainy seasons in this region, one from September to the beginning of December and the other from March to May. The average annual rainfall is 2000-3000 $\mathrm{mm}(\mathrm{Fa}, 1991)$ while temperatures vary between 19.5 and $21.9^{\circ} \mathrm{C}$ (Sabater $\mathrm{Pi}$, 1984).

One of the most singular characteristics of this area is its hilly topography. Monte Alen is part of the Niefang Mountains with altitudes from 400 to $1000 \mathrm{~m}$ a.s.l., reaching $1113 \mathrm{~m}$ in the Monte Alen peak.

There are no detailed descriptions of the vegetation except for Lejoly's (1994) inventory of species along a 1-km-long transect. The three most important vegetation types with regard to the distribution of primates are primary equatorial forest, secondary forest and native plantations (Guinea, 1946; Jones and Sabater Pi, 1971; Juste, 1993). Primary equatorial forest covers most of the park and is characterized by trees $50-60 \mathrm{~m}$ high with a relatively even subcanopy $(30-40 \mathrm{~m})$ and a sparse herbaceous understorey. This stratification is not so clear in the mountainous zones. Characteristic species belong to the families Caesalpinae, Mimosaceae, Moraceae, Sapotaceae and Burseraceae, among others. Grass-covered granitic inselberg domes (cerros cullpula), which emerge from the forest, are found at some points in the area. Secondary forests are the result of human activities, such as shifting agriculture, which is still common in the protected area, and forest exploitation, which was discontinued 5-10 years ago. This vegetation type can be found mainly along the eastern limit of the park along the

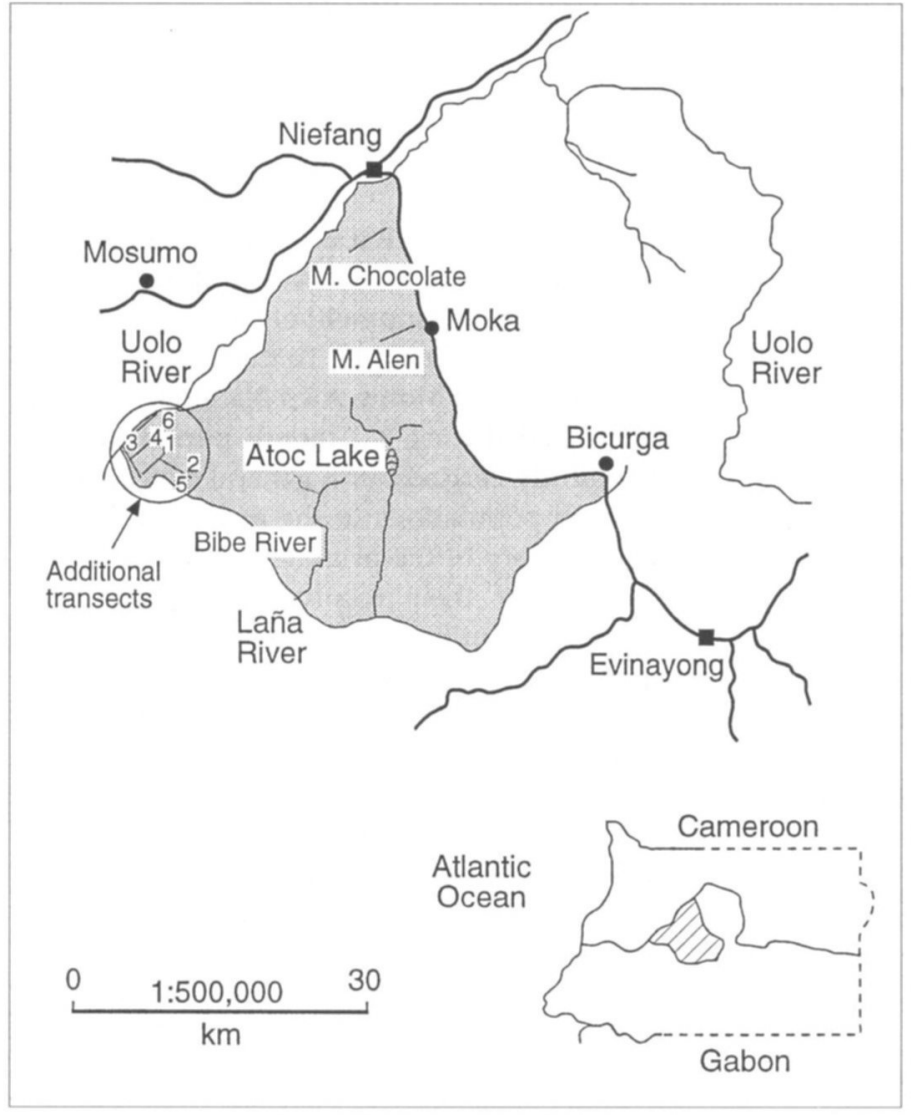

Figure 1. Monte Alen National Park, Equatorial Guinea showing location of transects for monkey censuses. 


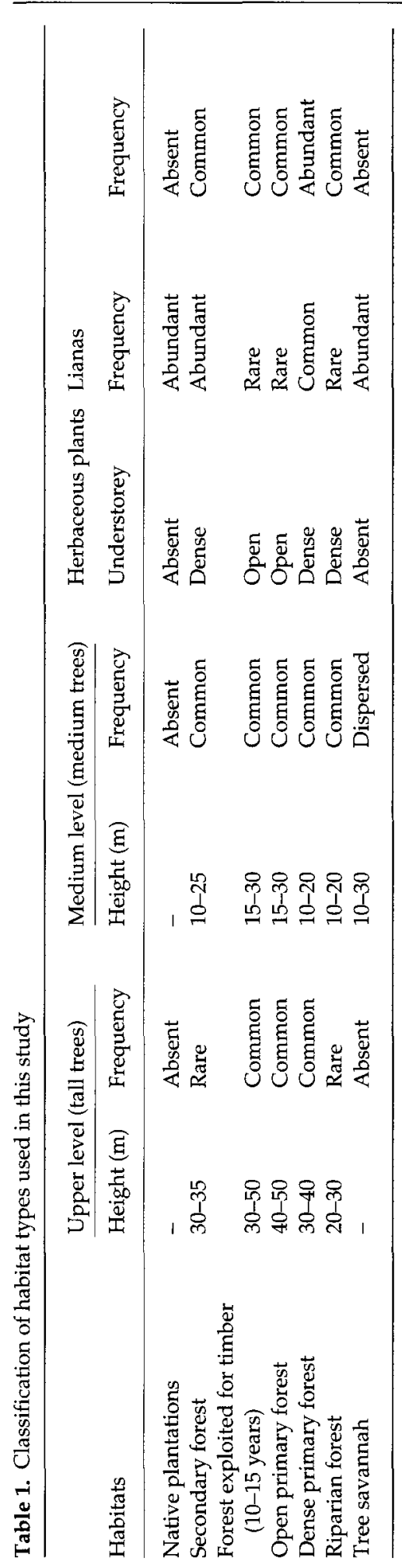

Niefang-Bicurga road. Tree composition varies depending on the stage of succession. The upper stratum of this forest is typically composed of young trees, such as Musanga cecropioides, while the lower strata may include bananas Musa spp., Vernonia spp., Costus spp. and Aframomum spp. The canopy reaches $6-10$ $\mathrm{m}$ with one or more subcanopies. Visibility near the ground is poor and human locomotion is difficult. Native plantations consist mainly of banana, cassava Manihot esculenta and sugar cane Saccharum spp.

In order to determine habitat use by primates in Monte Alen, we classified eight different habitat types in terms of structural features, representing general categories (NRC, 1981). Defining the species composition and frequency was not possible due to the limited duration of our study and our limited knowledge of the species involved. The eight habitat types considered are shown in Table 1.

Fieldwork for this study was conducted from May to November 1994. Three months (May to August) were dedicated to a census of monkeys (mangabeys, guenons and colobus), and 3 more months for gorillas and chimpanzees (August to October). Census methodology followed Struhsaker (1981) and Whitesides et al. (1988) for monkeys, and Tutin and Fernandez (1984) for gorillas and chimpanzees.

For the monkey census two $4.5-\mathrm{km}$-long transects (Monte Alen and Monte Chocolate), were set up on the eastern limit of the area. In addition, six transects covering a total of 20 $\mathrm{km}$ were placed near the western limits (Figure 1). For gorillas and chimpanzees, censuses were conducted along 34 different transects. In this case, each transect was opened the same day that the census was carried out. Figure 2 shows sampled areas according to length covered. Except for the Monte Alen transect, which was used previously for vegetation studies, the route of each transect was decided in advance by plotting the direction and distance on a 1:100,000 map.

Additional distribution and conservation data were obtained from surveys along forest trails and footpaths throughout the park and from interviews with the local inhabitants. 


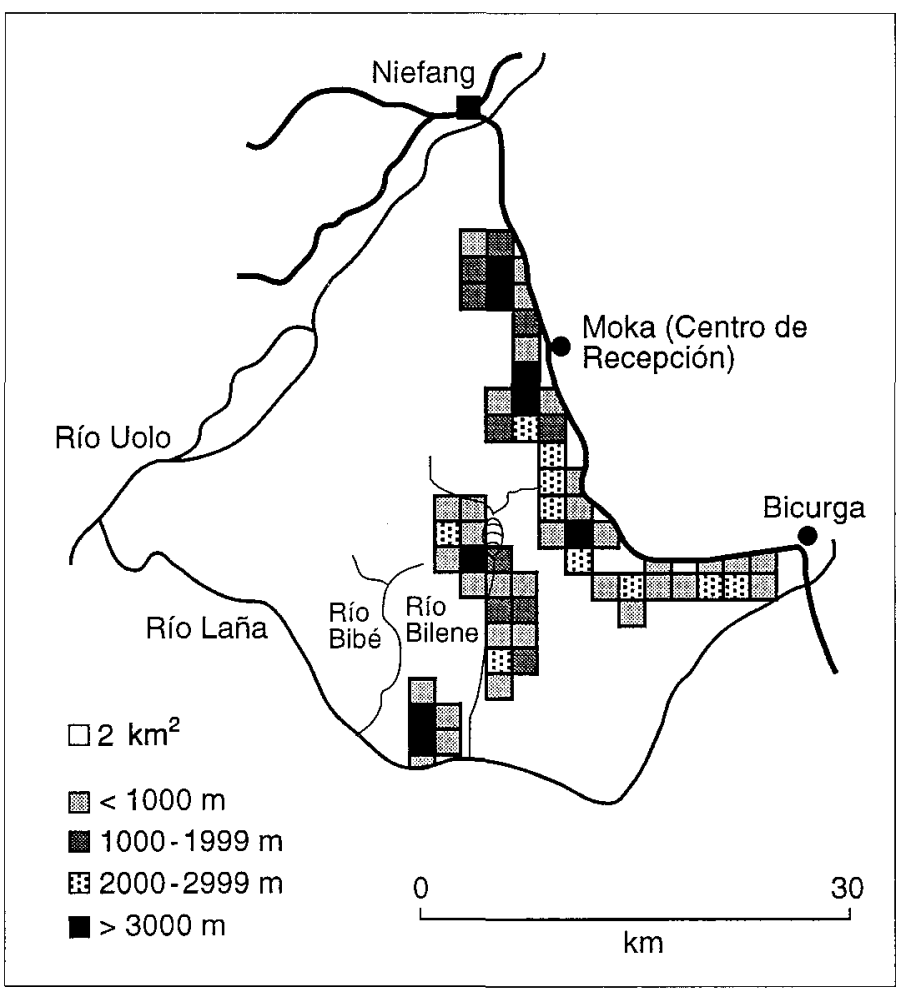

Figure 2. Sampled areas for gorilla and chimpanzee censuses. Shading indicates the no. of $\mathrm{m}$ covered in the survey.

\section{Results}

\section{Species recorded and distribution}

Fifteen species of primates, five nocturnal and ten diurnal, were confirmed in the park, with a possible sixteenth unidentified (Table 2). A synopsis of the present knowledge of distribution ranges for these primates in Monte Alen is given below.

Prosimian species: Arctocebus calabarensis, Perodicticus potto, Galago alleni, Galago demidovii and Galago elegantulus. All these species were recorded in the area along the NiefangBicurga road, and they are broadly distributed all over the park (Figure 3). They were found both in primary forest and in secondary forest near villages.

Mangabey species: The two mangabey species, the white-cheeked mangabey Cercocebus albigena and the white-collared mangabey Cercocebus torquatus are restricted to the Uolo and Laña river areas (Figure 3). The whitecheeked mangabey was observed in the basin of the Uolo and Laña rivers, near their confluence. Information from local people confirmed that this species is also found along the Uolo River, although it has probably disappeared from near Niefang due to overhunting. The white-collared mangabey was also observed along the Uolo River and, although not actually seen, probably exists in the Laña Basin, near the confluence of both rivers.

Both species were associated with the riparian forests along these rivers, although the white-cheeked mangabey was also observed in areas further away from the rivers. The white-collared mangabey was frequently associated with nipa palm trees Raphia spp. and swampy areas.

Mandrill: The mandrill Mandrillus sphinx is a terrestrial species, feeding on the forest floor by day and sleeping in the crowns of trees at night. It was observed in all surveyed areas of 
Table 2. Primate species in Monte Alen National Park, Equatorial Guinea

\begin{tabular}{lll}
\hline Scientific name & Fang name & English name \\
\hline Arctocebus calabarensis & Messechiri & Golden potto (Anguatibo) \\
Perodicticus potto & Agúm & Bosman's potto \\
Galago alleni & Eman & Allen's galago \\
Galago demidovii & Odzam & Dwarf galago \\
Galago elegantulus & Nsieñ & Needle-clawed galago \\
Cercocebus torquatus & Kacfung & White-collared mangabey \\
Cercocebus albigena & Kac & White-cheeked mangabey \\
Mandrillus sphinx & Esegue & Mandrill \\
Cercopithecus nictitans & Avem & Greater white-nosed monkey \\
Cercopithecus cephus & Nguemechog & Moustached monkey \\
Cercopithecus pogonias & Essuma & Crowned monkey \\
Cercopithecus neglectus & Fung & Brazza's monkey \\
Miopithecus talapoin & Onsem & Talapoin monkey \\
Colobus satanas & Nvuam & Black colobus \\
Pan troglodytes & Ngoro & Chimpanzee \\
Gorilla gorilla & Nguí & Gorilla \\
\hline
\end{tabular}

the park and it is broadly distributed over the entire area (Figure 3). This species inhabits both primary forest and secondary forest near villages.

Guenons: These are the most common primate species in the park. The greater white-nosed monkey Cercopithecus nictitans, the moustached monkey Cercopithecus cephus and the crowned monkey Cercopithecus pogonias were found in all surveyed areas (Figure 3). All three species were observed both in primary and secondary forest. Brazza's monkey Cercopithecus neglectus is found north of the Uolo River but park guards consider this species to be scarce south of the river, inside the protected area. It is possible that it exists near the confluence of the Uolo and Laña rivers.

Talapoin monkey: The talapoin monkey Miopithecus talapoin was detected in low-lying areas of the park (along the Laña and Uolo Rivers and along the Niefang-Bicurga road, from approximately $10 \mathrm{~km}$ before the village of Bicurga to the south; Figure 3). It was common both in primary and secondary forest.

Black colobus monkey: The black colobus monkey Colobus satanas was found in all surveyed areas. This species was frequently observed in central areas of the park and on the south and west edges, but was scarce along the Niefang-Bicurga road (the eastern boundary). Overhunting in the past and habitat destruction have determined the present distribution and abundance of this species in Monte Alen (Figure 3).

Gorillas and chimpanzees: Both gorillas Gorilla gorilla and chimpanzees Pan troglodytes were detected in all surveyed areas, although gorillas were more common in the mountainous areas, especially along the Niefang-Bicurga road, being scarce in low-lying areas of the park, along the Laña River and at the confluence of the Uolo and Laña Rivers. Both species are found in primary and secondary forest (Figure 3).

\section{Species-specific abundance}

Monkeys: We covered $225 \mathrm{~km}$ during 50 censuses made on the two $4.5-\mathrm{km}$-long transects, 30 along the Monte Alen transect and 20 along Monte Chocolate. Table 3 shows the total number of groups and the relative abundance of different species found on these two transects. The three most commonly sighted species on both transects were Cercopithecus 
nictitans (35.9 and 40.8 per cent of sightings, respectively), Cercopithecus cephus (43.5 and 28.9 per cent, respectively) and Cercopithecus pogonias (17.4 and 22.4 per cent, respectively). Significant differences were found between the mean number of groups of the three species, $C$. cephus, $C$. nictitans and $C$. pogonias, on the two transects $(Z=-0.33, P=0.7393 ; Z$ $=-1.59, P=0.1116$; and $Z=-1.67, P=0.0948$, Mann-Whitney $U$-test, respectively), so we have analysed separately data from the two transects.

Table 4 indicates abundance (groups $/ \mathrm{km}$ ) and mean distance covered to find any of the guenon groups in the different habitat types. On the Monte Alen transect, C. cephus was the most commonly seen species, both in open and dense primary forest $(0.37$ and 0.20 groups $/ \mathrm{km}$, respectively), it being necessary to cover on average $2.7 \mathrm{~km}$ in open primary forest and $5.0 \mathrm{~km}$ in dense primary forest to observe a group. However, on the Monte Chocolate transect the most commonly sighted species in open primary forest was $C$. nictitans $(0.41$ groups $/ \mathrm{km}$ or $2.4 \mathrm{~km}$ to observe a group), while in dense primary forest, $C$. nictitans and $C$. pogonias were the most common species $(0.12$ groups $/ \mathrm{km}$ or $8.3 \mathrm{~km}$ to observe a group). Overall, the three species were more abundant in open primary forest, where it was necessary to cover only $1.1 \mathrm{~km}$ to find a group, whereas in dense primary forest it was necessary to cover between 2.7 and $3.3 \mathrm{~km}$ to locate a group. Due to the small sample size the secondary forest was excluded from the analyis.

In order to complete the data obtained from the two $4.5-\mathrm{km}$ transects, we conducted six additional censuses covering $20-\mathrm{km}$ of primary forest (no distinction was made in this case between open and dense primary forest) on the western edge of the park. Table 3 shows the species-specific total number of sightings of

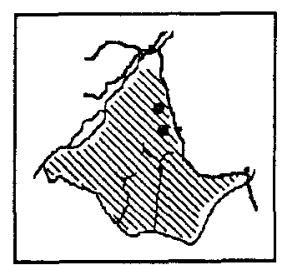

Arctocebus calabarensis Perodicticus potto Galago alloni

Galago demidovii Galago elegantulus

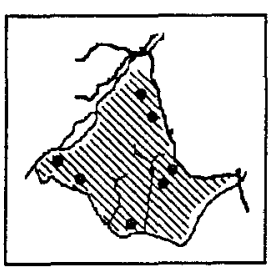

Mandrillus sphinx

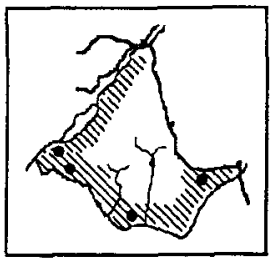

Miopithecus talapoin

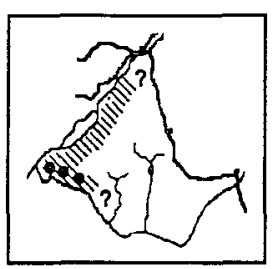

Cercocebus albigena
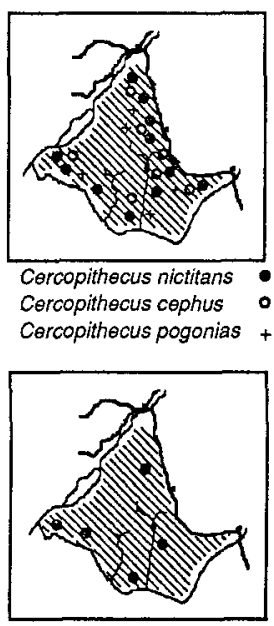

Colobus satanas
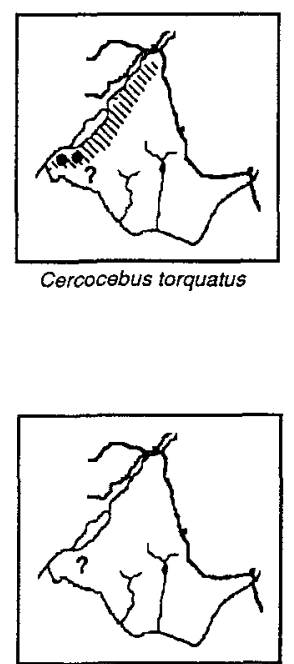

Cercopithecus neglectus

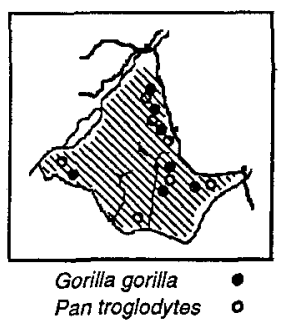

Figure 3. Distribution of primates in Monte Alen National Park. Dots indicate sightings and shaded areas indicate distribution. 
Table 3. Relative abundance of the different species observed in the Monte Alen and Monte Chocolate transects and number of sightings of groups and abundance in the additional transects

\begin{tabular}{|c|c|c|c|c|c|c|}
\hline \multirow[b]{2}{*}{ Species } & \multicolumn{2}{|c|}{ Monte Alen } & \multicolumn{2}{|c|}{ Monte Chocolate } & \multicolumn{2}{|c|}{ Western edge of park } \\
\hline & Groups & $\begin{array}{l}\text { Relative } \\
\text { abundance } \\
(\%)\end{array}$ & Groups & $\begin{array}{l}\text { Relative } \\
\text { abundance } \\
(\%)\end{array}$ & $\begin{array}{l}\text { No. } \\
\text { groups }\end{array}$ & $\begin{array}{l}\text { Groups / } \\
\mathrm{km}\end{array}$ \\
\hline Cercopithecus nictitans & 33 & 35.9 & 31 & 40.8 & 1 & 0.1 \\
\hline Cercopithecus cephus & 40 & 43.5 & 22 & 28.9 & 9 & 0.5 \\
\hline Cercopithecus pogonias & 16 & 17.4 & 17 & 22.4 & 2 & 0.1 \\
\hline Colobus satanas & 3 & 3.3 & 5 & 6.6 & 5 & 0.3 \\
\hline Cercocebus albigena & - & - & - & - & 2 & 0.1 \\
\hline M.andrillus sphinx & - & - & 1 & 1.3 & - & - \\
\hline Miopithecus talapoin & - & - & - & - & 2 & 0.1 \\
\hline Total & 92 & & 76 & & 21 & \\
\hline
\end{tabular}

groups and their abundance. In this area, $C$. cephus and Colobus satanas were the most commonly observed species $(0.5$ groups $/ \mathrm{km}$ and 0.3 groups $/ \mathrm{km}$, respectively). The higher abundance of $C$. satanas compared with the two $4.5-\mathrm{km}$-long transects should be noted, as well as the occurrence of two further species, Miopithecus talapoin and Cercocebus albigena.

Gorillas and chimpanzees: We covered a total of $84.9 \mathrm{~km}$ along the 34 censuses made, $33.7 \mathrm{~km}$ in dense primary forest, $31.6 \mathrm{~km}$ in open primary forest and 19.6 in secondary forest.
We found 208 gorilla nests and 333 chimpanzee nests. Of these, 145 gorilla nests $(69.7$ per cent) and 290 chimpanzee nests (87.1 per cent) were visible from the transect line. Eleven nests could not be attributed to either gorillas or chimpanzees. In the following analysis only nests visible from the transect line were considered.

Gorilla nests were more abundant in secondary forest $(5.15$ nests $/ \mathrm{km})$, while chimpanzee nests were mostly found in open primary forest ( 5.35 nests $/ \mathrm{km}$; Table 5 ).

The 145 gorilla nests were found in 44

Table 4. Abundance (groups $/ \mathrm{km}$ ) and mean distance to find a group

\begin{tabular}{|c|c|c|c|c|c|c|c|c|c|c|c|}
\hline \multirow[b]{2}{*}{ Habitat } & \multirow{2}{*}{$\begin{array}{l}\text { Dist. } \\
(\mathrm{km})\end{array}$} & \multicolumn{3}{|c|}{ No. groups } & \multicolumn{3}{|c|}{ Groups $/ \mathrm{km}$} & \multicolumn{4}{|c|}{$\begin{array}{l}\text { Mean distance }(\mathrm{km}) \\
\text { to find a group }\end{array}$} \\
\hline & & C.n.* & C.c. & C.p. & C.n. & C.c. & C.p. & C.n. & C.c. & C.p. & 3 spp. \\
\hline \multicolumn{12}{|l|}{ Monte Alen transect } \\
\hline Open primary forest & 75 & 24 & 28 & 15 & 0.32 & 0.37 & 0.20 & 3.1 & 2.7 & 5.0 & 1.1 \\
\hline Dense primary forest & 60 & 9 & 12 & 1 & 0.15 & 0.20 & 0.02 & 6.7 & 5.0 & 50.0 & 2.7 \\
\hline Secondary forest & 0 & & & & & & & & & & \\
\hline Total & 135 & 33 & 40 & 16 & & & & & & & \\
\hline \multicolumn{12}{|l|}{ Monte Chocolate transect } \\
\hline Open primary forest & 70 & 29 & 21 & 15 & 0.41 & 0.30 & 0.21 & 2.4 & 3.3 & 4.8 & 1.1 \\
\hline Dense primary forest & 17 & 2 & 1 & 2 & 0.12 & 0.03 & 0.12 & 8.3 & 16.7 & 8.3 & 3.3 \\
\hline Secondary forest & 3 & 0 & 0 & 0 & & & & & & & \\
\hline Total & 90 & 31 & 22 & 17 & & & & & & & \\
\hline
\end{tabular}

${ }^{*}$ C.n., C. nictitans; C.c., C. cephus; C.p., C. pogonias. 
groups, with a mean size of 3.3 (range 1-3). The 290 chimpanzee nests were found in 128 groups with a mean of 2.3 (range 1-16).

\section{Conservation status of primates}

Conservation measures began in the Monte Alen National Park in 1992, at the start of the ECOFAC project. The control of access to shotguns, which are commonly used to shoot primates, has been the measure that has contributed most to the mitigation of hunting pressure on primates. However, poaching still continues. Moustached monkeys, greater white-nosed monkeys and mandrills were commonly shot during the study period. One male gorilla was also shot during the last month of our study.

Trapping is also still common. Usually, snares are used to capture other species, such as forest duikers Cephalophus spp., Tragelaphus spp., pangolins Manis spp., African brushtailed porcupine Atherurus africanus, but sometimes poachers use other special traps for smaller primates (guenons and talapoin). The most common types are snares positioned on branches with a spring mechanism. When a monkey sets off the spring (usually by passing through it), a slip-knot tightens around its neck or one of its extremities. On other occasions, primates are accidentally captured in bird traps (mainly catapults with an automatic mechanism). We found one Allen's galago Galago alleni and one dwarf galago Galago demidovii captured in these.

Habitat destruction is another factor affecting primate conservation in the area. Native plantations and secondary forest are common along Niefang-Bicurga road and appear to be having a negative impact on species such as the black colobus. However, other species such as gorillas are common in this area. Gorillas were seen frequently during surveys in this area because they usually feed in native plantations, where Aframomum spp., of great importance for gorillas (Jones and Sabater $\mathrm{Pi}$, 1971), are abundant. There is no doubt that the future eradication of native plantations will enhance primate distribution and abundance in this zone.

The conservation status of primate populations reflects the impact of human activities in the area before 1992, current hunting pressure and habitat destruction, as well as the specific ecological requirements of particular species. Table 6 shows an estimation of the degree of threat for each species in Monte Alen. While species such as the three guenons, mandrill and talapoin are not threatened and are common and widely distributed, the two mangabeys are vulnerable due to their restricted range and abundance. Hunting pressure and habitat destruction could drastically affect these species. Colobus, one of the largest monkeys in the area, is preferred by poachers. Gorillas and chimpanzees, which some years ago were frequently hunted (12 gorillas and 2-20 chimpanzees per village per year; De la Riva, pers. comm.), are not threatened at present, being common all over the park and seen frequently near villages.

\section{Conclusions and recommendations}

Despite the small size of the country $(28,000 \mathrm{sq}$ $\mathrm{km}$ ), primate diversity is one of the highest in

Table 5. Nest abundance index of gorillas and chimpanzees

\begin{tabular}{lllllll}
\hline & Dist. & \multicolumn{2}{c}{ Gorillas } & & \multicolumn{2}{c}{ Chimpanzees } \\
Habitat & $(\mathrm{km})$ & No. nests & Nests $/ \mathrm{km}$ & & No. nests & Nests $/ \mathrm{km}$ \\
\hline Open primary forest & 31.6 & 10 & 0.32 & & 169 & 5.35 \\
Dense primary forest & 33.7 & 34 & 1.01 & & 115 & 3.41 \\
Secondary forest & 19.6 & 101 & 5.15 & & 6 & 0.31 \\
Total & 84.9 & 145 & & & 290 & \\
\hline
\end{tabular}


Table 6. Degee of threat of the primate species in Monte Alen National Park

\begin{tabular}{ll}
\hline Species & Degree of threat* \\
\hline Arctocebus calabarensis & IK \\
Perodicticus potto & IK \\
Galago alleni & IK \\
Galago demidovii & IK \\
Galago elegantulus & IK \\
Cercocebus torquatus & V \\
Cercocebus albigena & V \\
Mandrillus sphinx & NT \\
Cercopithecus nictitans & NT \\
Cercopithecus cephus & NT \\
Cercopithecus pogonias & NT \\
Miopithecus talapoin & NT \\
Colobus satanas & E/NT \\
Pan troglodytes & NT \\
Gorilla gorilla & NT \\
\end{tabular}

IK, Insufficiently Known: new studies are necessary to establish the degree of threat; V, Vulnerable: populations have limited distribution and/or ecological tolerance, and current rates of habitat alteration and/or hunting pressure are likely to intensify; or current rates of habitat alteration and/or hunting are slow but most populations have decreased significantly; E, Endangered: population is restricted to a very limited area, or with a very fragmented distribution. Populations are in danger of extinction due to major habitat alteration and/or severe hunting; NT, Not Threatened: species not included in categories described above. (Criteria modified from Oates, 1985 .)

Africa, with a total of 21 species (Oates, 1985), 15-16 of which are present in the Monte Alen National Park. Oates (1985) included black colobus and gorillas among the most threatened African primates, and rated the rest of the species as Vulnerable or Endangered. This area is therefore very important for the conservation of primate species.

The most important area in the park for primate conservation is the extreme west, near the confluence of the Uolo and Laña Rivers, where all the species recorded in Monte Alen are represented.

Differences recorded in primate abundance between the two $4.5-\mathrm{km}$ transects (relating to C. nictitans and C. cephus) may be related to past hunting pressure or to some habitat characteristics. Similarly, differences in primate composition and abundance in the area covered by the additional transect (the higher abundance of colobus or the presence of talapoin monkeys and mangabeys) are likely to be related to different habitat characteristics and hunting pressure. As regards habitat used by primates, it appears that guenons are more frequent in open primary forest, although we commonly observed these species near villages and in secondary forest. Further studies can help us understand habitat selection by these primates, an important consideration with respect to future management plans in the area.

Timber operations, poaching and agriculture have been prohibited within the park, but illegal hunting and some agriculture still continues, especially along the Niefang-Bicurga road. Although human activity should be kept to a minimum within the park, shifting agriculture can be managed in buffer zones, such as along the Niefang-Bicurga road, where sustainable-yield harvesting of more common species (Cephalophus spp., giant pouched rats Cricetomys emini, greater cane rat Thryonomys swinderanius, Manis spp. and Atherurus africanus) can also be tolerated. Rare species should, however, receive complete protection.

Every effort should be made to improve implementation of a protection and management plan for the area in the future, including an improvement in educational programmes and sustainable use of natural resources. The rearing in captivity of snails (Achatina spp.) and cane rats, which has just started, and the development of ecotourism, have the potential to become important contributors to the protection and adequate management of the area. Further studies on ecology and behaviour of primates are necessary to ensure the total protection of species. The value of gorillas as an attraction for ecotourism should be considered in the future.

\section{Acknowledgements}

This study ws carried out as part of the ECOFAC programme, supported by the European Union and developed by AGRECO-CIRAD Forêt and the Asociación Amigos de Doñana. I am grateful to 
Javier Castroviejo, Luis Arranz, Tica Cases, Carlos Lasso, Anabel Rial, Javier Juste, Jesus Ela, A. Ayong, Lorenzo, Restituto and many others, for assistance and support during the study and in the field. The collaboration of Guinean authorities was appreciated during the study. J. Castroviejo, F. Braza and C. Aveling reviewed an early draft of this paper.

\section{References}

Castroviejo, J., Juste, J., Castelo R. and Perez del Val, J. 1994. The Spanish co-operation programme in Equatorial Guinea: a ten-year review of research and nature conservation in Bioko. Biodiversity and Conservation, 3, 951-961.

Fa, J.E. 1991. Guinea Ecuatorial - Conservación y Manejo Sostenible de los Ecosistemas Forestales. IUCN, Gland, Switzerland and Cambridge, UK.

Fa, J.E. 1992. Conservation in Equatorial Guinea. Oryx, 26, 87-94.

Guinea, E. 1946. Ensayo Geobotánico de la Guinea Española. Instituto de Estudios Africanos, Consejo Superior de Investigaciones Científicas, Madrid, XII. 2vols.

Jones, C. and Sabater Pi, J. 1971. Comparative ecology of Gorilla gorilla (Savage and Wyman) and Pan troglodytes (Blumenbach) in Rio Muni, West Africa. Biblioteca Primatologica, 13, 1-96.

Juste, J. 1993. Guinea Ecuatorial. Principales ecosistemas terrestres y usos tradicionales y comerciales de sus recursos naturales. FORINDECO, unpublished report to FAO.

Lejoly, J. 1994. La biodiversité végétale dans le Parc National de Monte Alen. Report to ECOFACAGRECO. CTFT.

Oates, J. 1985. Action Plan for African Primate
Conservation: 1986-1990. IUCN/SSC Primate Specialist Group, New York.

NRC. National Research Council. 1981. Techiques for the Study of Primate Population Ecology. National Academy Press, Washington.

Sabater Pi, J. 1964. Distribución actual de los gorilas de llanura de Rio Muni. Zoo, Revista del Parque Zoológico de Barcelona, 3, 26-30.

Sabater Pi, J. 1978. Esquema para una ecología de los primates de Río Muni (República de Guinea Ecuatorial). Zoo, Revista del Zoológico de Barcelona, 32, 16-18.

Sabater Pi, J. 1984. Gorilas y Chimpancés del Africa Occidental. Fondo de Cultura Económica, México.

Struhsaker, T.T. 1981. Census methods for estimating densities. Techniques for the Study of Primate Population Ecology (ed. Subcommittee on Conservation of Natural Populations), pp. 36-80. National Academy Press, Washington.

Tutin, C.E.G. and Fernandez, M. 1984. Nationwide census of gorilla (Gorilla g. gorilla) and chimpanzee (Pan t. troglodytes) in Gabon. American Journal of Primatology, 6, 313-336.

Whitesides, G.H., Oates, J.F., Green, S.M. and Kluberdanz, R.P. 1988. Estimating primate densities from transects in an East African rain forest: a comparison of techniques. Journal of Animal Ecology, 57, 345-367.

Juan Enrique Garcia. Asociación Amigos de Doñana, c/Panamá, 6, 41012 Sevilla, Spain; and Estación Biológica de Doñana, Apartado 1056, 41080 Sevilla, Spain.

Jesus Mba. Proyecto ECOFAC, Parque Nacional Monte Alen, Casilla 317, Bata, Equatorial Guinea.1 